\title{
Estrategias de barrido visual realizadas enla percepción de imágenes estáticas y su integración con la memoria visual de corto plazo
}

\section{Autor: CIFUENTES CORREA, Yoiner}

Palabras claves: Memoria visual, Memoria Visual de Corto Plazo (VSTM),visión artificial, movimientos oculares, movimientos sacádicos, paradigma dedetección de cambio.

Fecha de elaboración del resumen: 01 de junio de 2010

\section{Descripción}

Los seres humanos están recibiendo permanentemente información a través de su sistema visual y el procesamiento de esta información visual le permitirá un mayor o menor grado de conocimiento y desempeño dentro del medio en que se mueve. La memoria en general y la memoria visual en particular es un proceso cognitivo básico que debe desarrollarse y está asociado con otras tareas cognitivas como la atención y procesos de comparación. En muchas actividades diarias es necesario hacer comparaciones futuras entre imágenes que ya fueron observadas, y en la medida en que el conocimiento espacial y el conocimiento de identidad de esas imágenes sea claro y preciso puede ser exitoso el proceso de comparación.La memoria visual de corto plazo (VSTM) es una etapa intermedia en los procesos de memoria visual y resulta ser fundamental en la consolidación de la memoria visual de largo plazo (VLTM). Al observar una imagen estática o una escena del mundo real, los movimientos oculares realizan un barrido con el fin de capturar e integrar la mayor cantidad de información posible. Estos movimientos oculares, llamados movimientos sacádicos, pueden estar definidos por una estrategia de barrido visual particular, y el presente trabajo estudia esas estrategias para asociarlas con la VSTM.

\section{Contenidos}

En el primer capítulo se describen las 3 subdivisiones de la memoria visual como son: memoria sensorial o icónica, memoria visual de corto plazo (VSTM) y memoria visual de largo plazo (VLTM). El segundo capítulo desarrolla ampliamente el marco teórico sobre la memoria visual de corto plazo (VSTM). En el tercer capítulo se estudian las relaciones entre los movimientos oculares y la memoria de escenas, en el cual se explican los roles funcionales de la memoria visual de corto plazo. El cuarto capítulo muestra la metodología utilizada en el desarrollo del trabajo e incluye: la pregunta de investigación y se plantean dos hipótesis, los objetivos propuestos, la justificación y las tres etapas utilizadas para la elaboración del trabajo. La primera etapa describe el dispositivo físico utilizado para realizar la experimentación y el ambiente computacional desarrollado en Matlab V7.5 que permite capturar y analizar los movimientos oculares de los sujetos participantes en la investigación. También se describe otro ambiente computacional en Matlab V7.5 cuya función es mostrar a los observadores los arreglos de prueba y los arreglos de muestra utilizados para evaluar la VSTM. En la etapa 2 se identifica la mejor estrategia de barrido visual utilizada por sujetos que tienen buena memoria visual de corto plazo, para lo cual se utilizó el paradigma de 
detección de cambio de un solo disparo. En la etapa 3 se desarrolla un ambiente computacional de Entrenamie to en Matlab V7.5, el cual recoge la mejor estrategia obtenida en la etapa 2. Con este ambiente computacional se entrena un grupo de estudiantes, grupo experimental, y posteriormente realizan la prueba de detección de cambio de un solo disparo. La misma prueba de detección de cambio se le realiza a otro grupo de estudiantes, grupo control, y se hace la comparación estadística de grupos. El capítulo 5 muestra las conclusiones del trabajo y en el capítulo 6 se dan unas sugerencias para trabajos futuros.

\section{Metodología}

El trabajo se desarrolla en tres etapas así:

Primera Etapa: diseño y construcción del dispositivo físico para capturar las trayectorias de barrido visual de los sujetos de experimentación y diseño del software acompañante del dispositivo.

Segunda etapa: Selección de un grupo de expertos quienes en su trabajo cotidiano están utilizando la VSTM y a quienes se les plantean problemas en un ambiente computacional con el paradigma de "detección de cambio". El dispositivo físico junto con el software captura las trayectorias seguidas por el ojo de estos sujetos durante la percepción de imágenes estáticas.

Esta información es analizada para identificar las estrategias de barrido seguidas por los sujetos, al solucionar los problemas planteados por el ambiente computacional. Tercera etapa: se escoge aleatoriamente un grupo experimental y un grupo de control. El grupo experimental es entrenado con la mejor estrategia de barrido visual identificada en la etapa dos. Se plantean tanto al grupo experimental como al grupo de control, los mismos problemas del ambiente computacional utilizado con los expertos. Los resultados obtenidos son analizados con respecto a la memoria visual de corto plazo y comparados para establecer si el entrenamiento dado al grupo experimental contribuyó para establecer diferencias entre los dos grupos.

\section{Conclusiones}

La estrategia visual más utilizada por los observadores expertos se toma como base para crear un ambiente computacional de entrenamiento llamado "entrenamiento.m", desarrollado en Matlab V7.5. Con este ambiente computacional fueron entrenados los sujetos del grupo experimental. Los tiempos utilizados por cada sujeto en el entrenamiento son diferentes, porque ésta es una condición individual que depende de la capacidad de memoria visual que tenga cada uno. Por tanto, ese tiempo de entrenamiento es una condición no manipulable.

Las mejores estrategias de barrido visual identificadas en la etapa 2 y aplicadas en la etapa 3 como entrenamiento al grupo experimental, no evidenciaron optimización en la memoria visual de corto plazo (VSTM), respondiendo así a la pregunta de investigación, y según se establece en los resultados de la comparación de grupos con la prueba T. Al no existir diferencias significativas entre los dos grupos, se confirma la hipótesis $\mathrm{H} 1$ y se rechaza la hipótesis $\mathrm{H} 2$.

El 100\% de los observadores expertos tuvieron acierto en la tarea de detección de cambio de los arreglos 12, 19, 112. El 95\% de los observadores expertos tuvieron acierto en la tarea de detección de cambio del arreglo 16. Los arreglos 12, 16, 112, contienen 4 ítems cada uno y el arreglo 19 contiene 5 ítems. Se confirman así los hallazgos de Luck y Vogel (1997) quienes afirman que el máximo rendimiento en la capacidad de memoria visual de corto plazo en tareas de detección de cambio se obtiene cuando los arreglos observados tienen hasta 4 y 5 ítems. 